\title{
Phytoremediation Using Constructed Wetlands to Treat Reverse Osmosis Rejected Concentrates
}

\author{
Athapattu B.C.L. ${ }^{*}$, Thalgaspitiya T.W.L.R. ${ }^{2}$, Yasaratne U.L.S. ${ }^{2}$ and Vithanage M. ${ }^{3}$ \\ ${ }^{1}$ Department of Civil Engineering, Open University of Sri Lanka \\ ${ }^{2}$ National Water Supply and Drainage Board, Rathmalana, Sri Lanka \\ ${ }^{3}$ Chemical and Environmental Systems Modeling Research Group, National Institute of Fundamental \\ Studies, Sri Lanka \\ *bcliy@ou.ac.lk
}

\begin{abstract}
Reverse Osmosis (RO) water purification systems are common over many farming areas of North Central Province in Sri Lanka for providing potable water to protect public from the Chronic Kidney Disease of unknown etiology (CKDu). About 50-70\% of raw water with higher concentrations of ions release from RO systems with no beneficial use. Such a practice will end up with long term environmental impacts to soil and groundwater and therefore it is at utmost requirement to find suitable remedial technique. This research was focused to investigate the potential remedial measures for concentrated contaminants of RO rejected water through phytoremediation process using Constructed Wetlands $(\mathrm{CW})$, before discharging into the environment.
\end{abstract}

A field experiment was carried out focusing on the Sangilikanadarawa at Medawachchiya community based RO water supply unit. Two types of constructed wetlands (CW): surface and subsurface water bio-geo $\mathrm{CW}$ were established and tested to measure the removal efficiency of RO concentrates through phytoremediation and filter materials. Locally available soil, Calicut tile and biochar were used with proportions of $81,16.5$ and $2.5 \%$ by weight respectively as filter materials. Vertiver Grass and Scirpus Grossus were carefully selected for the sub surface wetland while Water Lettuce and Water Hyacinth were chosen for free water surface $\mathrm{CW}$. Both constructed wetlands were fed with a uniform flow of RO concentrate and water quality parameters were tested periodically against two controls systems for a given hydraulic retention time. The results showed that the Total Dissolved Solids, Hardness, Total Alkalinity and Fluoride were reduced significantly and met desirable levels of stipulated ambient standards. This study indicated a great promise of purifying aforesaid contaminants of water which is obvious and considerable in ground water sources in the North Central Province, with a very low construction and maintenance cost in comparison to other water purifying methods as this approach directly dealt with locally available aquatic plants and ecofriendly filter materials. Therefore the invented bio-geo constructed wetland is an economical and effective option for reducing high concentrations of $\mathrm{RO}$ rejected water before discharging into the inland waters.

Keywords: Reverse osmosis, RO concentrate, Phytoremediation, Constructed wetlands, biochar

Proceedings of the International Forestry and Environment Symposium 2016, Department of Forestry and Environmental Science, University of Sri Jayewardenepura, Sri Lanka. 